\title{
La banca costarricense y sus retos, desde una perspectiva de ética, imagen, credibilidad y confianza
}

\author{
The costa rican banking and its challengers, from a perspective of \\ ethics, image, credibility and trust
}

Lic. Juan Pablo Alcázar Villalobos

Universidad Nacional, Costa Rica

juanpalcazar@gmail.com

\author{
MSc. Osvaldo Carvajal Cascante \\ Universidad Nacional, Costa Rica \\ osvaldo.carvajal.cascante@una.cr
}

\author{
MSc. Gustavo Mauricio Vallejo Esquivel \\ Universidad Nacional, Costa Rica \\ gustavo.vallejo.esquivel@una.cr
}

Fecha de recepción: 29 de enero de 2019

\section{RESUMEN}

Este artículo procura generar consciencia en la población sobre la trascendencia de la banca en el desarrollo nacional y cómo la confianza depositada por los habitantes logra que el sistema financiero nacional se desarrolle y evolucione de forma más ágil, al establecerse la regla de que, cuanta más confianza, más transacciones y satisfacción de necesidades; es decir, la ética desarrollada desde una perspectiva del comportamiento del individuo en el sector bancario, donde valores como profesionalismo, diligencia, responsabilidad y honestidad resultan determinantes para llevar a cabo el negocio y una buena gestión financiera, de la que dependen sumas considerables de dinero.

\section{ABSTRACT}

This article seeks to raise awareness among the national population about the importance of the banking sector for the national development and how trust placed in it by the inhabitants makes the national financial system perform and evolve with more flexibility. This can be accomplished by establishing the rule according to which the greater the trust, the more transactions and satisfaction of needs there are. In other words, the ethics developed from a perspective of the individual's behavior in the banking sector implies that values such as professionalism, diligence, responsibility and honesty are decisive to carry out the business and a sound financial management, on which considerable sums of money depend.
Fecha de aceptación: 31 de marzo de 2020

\section{RÉSUMÉ}

Cet article vise à susciter une prise de conscience parmi la population sur la transcendance de la banque dans le développement national et la façon dont la confiance placée en elle par les habitants favorise le développement plus flexible du système financier national. Ceci est possible en établissant la règle selon laquelle le plus il $\mathrm{y}$ a de la confiance, le plus il y a de transactions et de besoins satisfaits. En d'autres mots, l'éthique développée sous l'angle du comportement individuel dans le secteur bancaire implique que des valeurs comme professionnalisme, diligence, responsabilité et honnêteté sont déterminantes pour faire fonctionner l'entreprise et effectuer une bonne gestion financière, dont dépendent des sommes d'argent considérables.

\section{RESUMO}

Este artigo busca gerar consciência na população sobre a transcendência da banca no desenvolvimento nacional e como a confiança depositada nela pelos habitantes procura um desenvolvimento e uma evolução mais ágil do sistema financeiro nacional. Isto e possível ao se estabelecer a regra segundo a qual a mais confiança, mais transações e satisfação de necessidades. Em outras palavras a ética desenvolvida desde uma perspectiva do comportamento do indivíduo no setor bancário, implica que valores como profissionalismo, diligência, responsabilidade e honestidade resultam determinantes para realizar o negócio e uma boa gestão financeira, da qual dependem quantias consideráveis de dinheiro.
PALABRAS CLAVE:

\section{ÉTICA,}

FINANZAS,

IDONEIDAD,

RECURSOS,

SEGURIDAD.
KEY WORDS:

ETHICS,

FINANCES,

SUITABILITY,

RESOURCES,

SECURITY
PALAVRAS CHAVE:

ÉTICA

FINANÇAS,

ADEQUAÇÃO,

RECURSOS,

SEGURANÇA.
MOTS CLÉS:

ÉTHIQUE,

FINANCES,

PERTINENCE,

RESSOURCES,

SÉCURITÉ. 


\section{INTRODUCCIÓN}

A finales del año 2016 y principios del 2017, estalla en Costa Rica un escándalo noticioso asociado con el uso de recursos de la banca estatal para financiar actividades empresariales privadas de alto riesgo; movimientos y decisiones que en pleno año 2020 continúan bajo investigación por parte de las autoridades competentes. En este marco, surgieron varios espacios de reflexión sobre la importancia de blindar la banca estatal contra una serie de actividades de corte político que ponen en riesgo su integridad financiera y comprometen la ética, la imagen y la confianza en estas instituciones.

El diccionario de la Real Academia Española define ética como el "conjunto de normas morales que rigen la conducta de la persona en cualquier ámbito de la vida”. A esto, agregamos que, por ser un comportamiento, corresponde única y exclusivamente al individuo, toda vez que depende de él sin importar si es gestor o jerarca de un banco o cliente de este, y que la utilización de este concepto no debe pretender encontrarse en la misión, visión y valores estratégicos de una organización, sino que radica en la forma en que la persona se comporta y actúa según sus normas morales.

Si se retoman los hechos sucedidos en los últimos cuatro años, quedan en evidencia grandes deficiencias en el comportamiento moral de los individuos encargados de la toma de decisiones en los altos puestos de los bancos, lo cual ha producido pérdidas económicas considerables y ha deteriorado significativamente dos de los principales activos intangibles de las instituciones de intermediación financiera: la confianza y la imagen.

Si bien es cierto en Costa Rica existen leyes, reglamentos y procedimientos de control de las operaciones bancarias que se realizan en el territorio nacional, el incumplimiento de esta normativa ha generado situaciones como las del Banco Anglo Costarricense, BICSA, Bancrédito y el Banco de Costa Rica, donde el común denominador ha sido la mala toma de decisiones por parte de los jerarcas, influenciadas por el clientelismo, favoritismo y amiguismo, por encima de las buenas prácticas del gobierno corporativo.

La investigación y desarrollo de este artículo tiene como objetivo reflexionar sobre cómo este tipo de prácticas pueden lesionar y poner en peligro la banca estatal, patrimonio de los costarricenses, desde una perspectiva de los factores de riesgo que comprometen la ética bancaria al tomar decisiones en los altos mandos.

Paralelo a la presente investigación, los autores pretenden impulsar un proyecto de ley en la Asamblea Legislativa, bajo la modalidad de propuesta ciudadana, la cual insistiría en la necesidad de que los nombramientos de jerarcas y directivos de los bancos del Estado sean realizados por el Poder Legislativo, para asegurar la absoluta independencia de este poder de la república y así eliminar un posible tráfico de influencias en los negocios, operaciones y decisiones de los bancos.

\section{DESARROLLO}

Desde los inicios de la banca en Mesopotamia, aproximadamente en el año 2000 a.C., el mecanismo de este negocio siempre ha estado basado en la confianza que se genera entre los agentes superavitarios, que corresponden a aquellos que no consumen todos sus ingresos, y los agentes deficitarios, que requieren recursos para satisfacer sus necesidades.

Para el caso de Costa Rica, en cuanto al negocio de la banca en tiempos de la colonia, la vida productiva de la naciente nación hizo necesario que se establecieran diversas formas de pago para la compra y venta de productos y servicios. No es sino hasta las administraciones de Braulio Carrillo Colina, de 1835 a 1842, cuando se emite el primer papel moneda nacional como parte del nuevo sistema monetario del país, impulsado para dar soporte al modelo agroexportador cafetalero de la naciente república.

Posteriormente, en 1858, abre sus puertas el Banco Nacional Costarricense, primera casa bancaria del país, la cual emite papel moneda en emisiones de 1, 2, 10 y 20 pesos, con sus series A y B. En 1896, entra en vigencia una reforma monetaria que establece el colón como moneda nacional y, en 1900, gracias a la Ley de Bancos, otras casas bancarias pudieron emitir billetes, siempre y cuando tuvieran un capital de un millón de colones de reserva. Más adelante y precisamente durante la administración del joven herediano Alfredo González Flores, de 1914 a 1917, se anuncia la creación de un banco hipotecario para apoyar el desarrollo productivo y la economía de Costa Rica.

En 1948, se nacionaliza la banca y surge la necesidad de integrar de manera adecuada y eficiente el sistema bancario nacional. Se crea así, en enero de 1950, el Banco Central de Costa Rica, mediante la Ley 1130, como órgano central e independiente que rige la política económica, monetaria y crediticia del país. 
Cabe agregar que en el título XVI, artículo 189, de la Constitución Política de Costa Rica, se establece que los bancos del Estado son instituciones autónomas y, por ende, sujetas a las regulaciones de carácter normativo aplicadas a los bancos y, en especial, a la normativa que deben cumplir por tratarse de fondos públicos.

Es importante agregar que el actual sistema bancario costarricense inició su último cambio a partir del segundo quinquenio de los años noventa del siglo pasado y, dentro las modificaciones más relevantes, está la creación del Consejo Nacional de Supervisión del Sistema Financiero (CONASSIF), órgano colegiado de alta dirección encargado de otorgar uniformidad e integridad a todas y cada una de las operaciones que se realizan a través del sistema financiero, regulando y supervisando su quehacer.

El CONASSIF tiene bajo su dependencia a la Superintendencia General de Entidades Financieras (SUGEF), la Superintendencia General de Valores (SUGEVAL), la Superintendencia General de Pensiones (SUPEN) y la Superintendencia General de Seguros (SUGESE).

En la figura 1, se representa la posición que tiene el CONASSIF dentro del sistema financiero costarricense.

Banco Central

de Costa Rica

BCCR

Consejo Nacional de Supervición

del Sistema Financiero

CONASSIF

Superintendencia General

de Identidades Financieras SUGEF
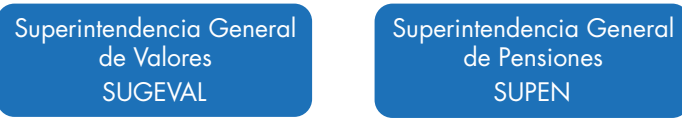

Figura 1. Conformación del sistema financiero nacional. Fuente: elaboración propia.

De su génesis, el sistema bancario nacional ha gozado de la confianza de la población costarricense, lo cual ha contribuido a apoyar el desarrollo del país tanto en lo público como en lo privado, llegando a convertirse hoy en un importante músculo financiero de la nación, orientado a impulsar diferentes sectores de la economía.

En la tabla 1 se presenta en forma cronológica la principal normativa legal aprobada por el sistema financiero nacional de Costa Rica, diciembre de 2019.

\begin{tabular}{|c|c|}
\hline Fecha & Documento \\
\hline 7/11/1949 & Constitución política de Costa Rica \\
\hline $27 / 9 / 1953$ & $\begin{array}{c}\text { Ley orgánica del sistema bancario nacional, } \\
\text { no. } 1644\end{array}$ \\
\hline 29/8/1968 & $\begin{array}{l}\text { Ley de asociaciones cooperativas y creación del } \\
\text { instituto de fomento cooperativo, no. } 4179\end{array}$ \\
\hline 19/7/1969 & $\begin{array}{c}\text { Ley orgánica del banco popular y de desarrollo } \\
\text { comunal }\end{array}$ \\
\hline $18 / 8 / 1970$ & $\begin{array}{c}\text { Ley sobre destino de utilidades que obtengan los } \\
\text { bancos por bienes adjudicados en remate (ley } \\
4631 \text { ) }\end{array}$ \\
\hline 22/9/1972 & $\begin{array}{l}\text { Ley reguladora de empresas financieras } \\
\text { no bancarias, no. } 5044\end{array}$ \\
\hline 7/11/1984 & Ley de asociaciones solidaristas, no. 6970 \\
\hline $13 / 11 / 1986$ & $\begin{array}{l}\text { Ley del sistema financiero nacional para la vivienda } \\
\text { y creación del banhvi, no. } 7052\end{array}$ \\
\hline $22 / 11 / 1988$ & $\begin{array}{l}\text { Ley de modernización del sistema financiero de la } \\
\text { república, no. } 7107\end{array}$ \\
\hline
\end{tabular}

\begin{tabular}{|c|c|}
\hline Fecha & Documento \\
\hline 4/9/1990 & $\begin{array}{l}\text { Reglamento a la Ley Reguladora de Empresas } \\
\text { Financieras no Bancarias, No. 19530-H }\end{array}$ \\
\hline $24 / 4 / 1994$ & $\begin{array}{l}\text { Ley reguladora de la actividad de intermediación } \\
\text { financiera de las organizaciones cooperativas (Ley } \\
7391 \text { ) }\end{array}$ \\
\hline $27 / 4 / 1994$ & $\begin{array}{l}\text { Ley Reguladora de la Actividad de Intermediación } \\
\text { Financiera de la Organizaciones Cooperativas, } \\
\text { No. } 7391\end{array}$ \\
\hline $27 / 11 / 1995$ & Ley Orgánica del Banco Central, No. 7558 \\
\hline $27 / 11 / 1995$ & Ley Orgánica del Banco Central de Costa Rica (Ley 7558) \\
\hline $6 / 3 / 1996$ & $\begin{array}{l}\text { Reglamento General de la Contratación } \\
\text { Administrativa, Decreto Ejecutivo No. 25038-H }\end{array}$ \\
\hline $27 / 1 / 1998$ & Ley Reguladora del Mercado de Valores, No. 7732 \\
\hline $24 / 10 / 2001$ & $\begin{array}{c}\text { Creación del Fideicomizo para la Protección y el } \\
\text { Fomento Agropecuario para Pequeños y Medianos } \\
\text { Productores, No. } 8147\end{array}$ \\
\hline $11 / 1 / 2002$ & $\begin{array}{l}\text { Ley Sobre Estufefacientes, Sustancias Psicotrópicas, } \\
\text { Drogas de Uso no Autorizado, Legitimación de } \\
\text { Capitales y Actividades Conexas, No. } 8204\end{array}$ \\
\hline
\end{tabular}




\begin{tabular}{|c|c|}
\hline Fecha & Documento \\
\hline $5 / 6 / 2002$ & $\begin{array}{c}\text { Manual de Normas Generales de Control Interno para la Contraloría General de la República y las Entidades y Órganos Sujetos } \\
\text { a su Fiscalización, No. M-1-2002-CO-DDI }\end{array}$ \\
\hline $31 / 7 / 2002$ & Ley General de Control Interno, No. 8292 \\
\hline $5 / 11 / 2002$ & Interpretación Auténtica del Inciso C) del Artículo 23 de la Ley 7092 de Impuesto Sobre la Renta, No. 8320 \\
\hline $5 / 11 / 2002$ & Democratización de las Instancias de Decisión del Banco Popular y Desarrollo Comunal, No. 8322 \\
\hline $29 / 4 / 2003$ & $\begin{array}{c}\text { Aprobación de Asistencia Financiera del Banco Hipotecario de la Vivienda para el Pago de Bonos Familiares de } \\
\text { Vivienda, No. } 8353\end{array}$ \\
\hline $20 / 1 / 2004$ & $\begin{array}{c}\text { Reglamento Relativo a la Información Financiera de Entidades, Grupos y Conglomerados Financieros, Artículo } 13 \\
\text { del Acta de la Sesión 41 1-2003 }\end{array}$ \\
\hline $29 / 4 / 2004$ & Ley Orgánica del Banco Popular y de Desarrollo Comunal, No. 4351 \\
\hline $29 / 10 / 2004$ & Ley Contra la Corrupción y el Enriquecimiento llícito en la Función Pública, No. 8422 \\
\hline $3 / 11 / 2004$ & $\begin{array}{l}\text { Reglamento General a la Ley Sobre Estupefacientes, Sustancias Psicotrópicas, Drogas de uso no Autorizado, } \\
\text { Legitimación de Capitales y Actividades Conexas, No. } 31684-M \text {-MSP-H-COMEX-S }\end{array}$ \\
\hline
\end{tabular}

La tabla 2 se elabora con el fin de mostrar en forma cíclica los eventos más relevantes, a nuestro criterio, en el desarrollo de la banca de Costa Rica.

Tabla 2. Eventos relevantes en el desarrollo de la banca costarricense, diciembre de 2019.

\begin{tabular}{|c|c|c|c|}
\hline Año & Evento & Año & Evento \\
\hline 1858 & Banco Nacional de Costa Rica & 1945 & Banco Central de Costa Rica \\
\hline 1859 & Cierre Banco Nacional de Costa Rica & 1948 & Se decreta la nacionalización bancaria \\
\hline 1863 & Banco Anglo Costarricense & 1969 & Banco Poular y de Desarrollo Comunal \\
\hline 1867 & Banco Nacional de Costa Rica & 1976 & BICSA \\
\hline 1872 & Banco Rural de Crédito & 1987 & Crisis del Sistema Financiero Informal \\
\hline 1877 & Cierre Banco Nacional de Costa Rica & 1994 & Cierre Banco Anglo Costarricense \\
\hline 1877 & Banco de la Unión / Banco de Costa Rica & 1995 & $\begin{array}{c}\text { Ruptura del monopolio de las cuentas corrientes y } \\
\text { redescuento }\end{array}$ \\
\hline 1890 & $\begin{array}{l}\text { Banco de la Unión se transforma en actual } \\
\text { Banco de Costa Rica }\end{array}$ & 1995 & Nace la SUGEF \\
\hline 1905 & Banco Comercial de Costa Rica & 1998 & Crisi Financiera del Movimiento Cooperativo \\
\hline 1908 & Banco Mercantil de Costa Rica & 2004 & Cierre de operaciones de BICSA \\
\hline 1914 & Banco Internacional de Costa Rica & 2008 & Crisis Económica Mundial \\
\hline 1918 & Banco Crédito Agrícola de Cartago & 2016 & $\begin{array}{c}\text { Situación de financiamiento de cemento chino } \\
\text { banca pública y privada }\end{array}$ \\
\hline 1938 & Banco Nacional de Costa Rica & 2017 & Cierre de Bancrédito \\
\hline
\end{tabular}

Fuente: elaboración propia.

\section{Papel de la banca costarricense}

Un buen ejemplo del papel de la banca costarricense y su contribución con el desarrollo es la respuesta del país ante la crisis económica mundial de 2008, gracias a estrategias como la generación de una cantidad mayor de recursos a un menor costo financiero (margen de intermediación) y colocación responsable de crédito, entre otras, lo cual permitió mantener al sistema financiero nacional estable antes, durante y después de la crisis. 
Pese al desarrollo y tamaño de la banca costarricense y a que esta no posee la misma envergadura de países como Estados Unidos de América, el enfrentamiento de la crisis por parte del sistema financiero nacional impidió que se replicaran situaciones y afectaciones como las acontecidas con las economías de naciones como España, Estados Unidos, Hungría, Grecia, Irlanda, Islandia, Italia y Portugal, por mencionar unas.

No obstante, una vez ubicada la banca costarricense en un contexto socioeconómico, se contrapone con una situación que trasciende el ámbito meramente del negocio como tal, ya que, producto de los acontecimientos de los últimos años, se ha generado una férrea discusión sobre las debilidades de estas instituciones de gran relevancia para el desarrollo del país.

Se ha informado a la población, por parte de medios periodísticos, la Asamblea Legislativa, la SUGEF y distintas investigaciones, entre otras, sobre presuntos manejos indebidos en diferentes operaciones bancarias y supuestos tráficos de influencias que involucran a altos funcionarios tanto del Gobierno, como de entidades bancarias nacionales, asunto que ha afectado la credibilidad en estas instituciones.

En el ámbito nacional, quien esté inmerso en temas bancarios ha notado cómo se levantan voces de diferentes sectores, las cuales exigen a los supremos poderes de la república tomar acciones contundentes para asegurar que la banca nacional se libere o se blinde de fardos políticos y de manejos indebidos que ponen en riesgo su reputación y permanencia.

Según informes legislativos e instancias de control, en los últimos años ha sido evidente cómo el denominado tráfico de influencias ha permeado los negocios, operaciones y decisiones de los bancos. Así, surge la necesidad de que la banca estatal garantice transparencia en los negocios que gestiona y que se estandaricen tanto los requisitos como la normativa, para así evitar estas y otras anomalías.

Indiferentemente de que se ubiquen operaciones en la banca pública o en la privada, el grado de responsabilidad al tomar decisiones es la misma, pues al estar de por medio el ahorro de terceros, producto de la intermediación financiera abierta, estos son sujetos de control por parte de la normativa del sistema bancario costarricense, es decir, la SUGEF. Trátese de un intermediario financiero público o de uno privado, y a diferencia de una empresa privada, un banco no se administra como su junta directiva disponga, sino como está debidamente normado dentro del ordenamiento jurídico.

No debe dejarse de lado el papel protagónico que posee la Superintendencia General de Entidades Financieras, como ente fiscalizador, pues buena parte de la población considera que su papel es de garante, en el entendido de que un concepto es fiscalizar y otro es respaldar, y que no debe confundirse fiscalización con un contrato de cobertura de la gestión del negocio bancario. De igual forma, se considera que la normativa actual de SUGEF es lo suficientemente amplia para los intermediarios financieros costarricenses, siendo lo importante su debido cumplimiento y aplicación.

En cuanto a las juntas directivas se refiere, se ha evidenciado que estas han sido permisivas y que, por la naturaleza de los nombramientos de los directivos, estas han venido respondiendo a intereses políticos, empresariales, sectoriales y no precisamente a la razón de ser del banco.

Con todo lo acontecido en el sector bancario en los últimos cuatro años, se esperaría que los jerarcas del sector financiero hayan aprendido una buena lección, pues la ética y el trabajo que se realiza en la banca han sido fuertemente cuestionados.

En concordancia con este alcance, se genera la pregunta: ¿cuál es la importancia de desligar los nombramientos realizados por el Poder Ejecutivo? En este sentido, las máximas instancias de los intermediarios financieros deben tener muy clara la responsabilidad sobre los recursos que manejan sus gerentes, subgerentes, directores de las unidades especializadas, la jurídica, la administrativa y los directores bancarios, para que, cuando se otorguen créditos, se asegure el retorno de la inversión. Se debe plantear si funcionaría mejor la gestión si el nombramiento de estos puestos se desliga del Poder Ejecutivo para darles verdadera independencia en su función al tomar decisiones.

En una sana y transparente administración, el gobierno corporativo establece un perfil idóneo para el directivo y, en la parte administrativa, todas las empresas establecen reglas claras de contratación, competencias técnicas y habilidades personales indispensables que deben ser tomadas en consideración al ocupar un puesto.

Bajo la premisa anterior y dando esa independencia al jerarca, se logra un mayor empoderamiento en caso de tener que decir que NO en trámites de amigos, miembros de la cúpula, empresarios influyentes o del propio presidente de la república. 
Al ubicar el estudio del lado del individuo, existe una gran responsabilidad en el momento en que se acepta un puesto, toda vez que deben prevalecer la consciencia y responsabilidad de asegurar que se contrata a la persona con la idoneidad requerida, los conocimientos necesarios y la experiencia para asumir de una forma óptima sus funciones; de no cumplirse lo anterior, se estaría a las puertas de una mala gestión, con toda la responsabilidad civil y penal que esto conlleva, aparte de poner en riesgo el patrimonio de la institución que se representa.

La idoneidad que poseen las personas a las que se designa en puestos en juntas directivas de bancos, entidades financieras y altos mandos es fundamental como mecanismo de preparación e inducción para entender el negocio bancario y debe ir de la mano con principios éticos y morales intachables, necesarios para asumir la responsabilidad que pesa sobre sus hombros y garantizar excelencia en la gestión.

\section{Ética bancaria}

Se puede definir como la forma en la que se desenvuelve un individuo en el sector bancario, en donde valores como profesionalismo, diligencia y responsabilidad resultan determinantes para llevar a cabo el negocio y una buena gestión financiera.

Debe reconocerse y entenderse este concepto como honestidad, en el entendido de que se le asignan dos momentos temporales:

- Aceptación del cargo: cuando se acepta el cargo y se analiza si el individuo está o no capacitado para desempeñarlo y si cuenta con la formación académica necesaria.

- Desempeño de la actividad: si acepta el cargo, debe evitar conflictos de interés y contar con gran sentido de transparencia.

Aunado a lo anterior, resultan importantes el compromiso y la dedicación, ya que, por más competencias y formación que posea la persona, es importante que cuente con la dedicación de tiempo para asumir las responsabilidades inherentes al puesto, ya que las instituciones financieras son muy complejas y atienden asuntos muy delicados que deben analizarse con profundidad, pues están en juego cantidades importantes de dinero.

Para el caso de los nombramientos y representaciones, la ética juega un papel muy importante que es como una moneda: en una cara se encuentra quién nombra y en la otra cara quién representa, ambas orientadas a una designación que no puede responder a botines políticos, sino más bien a una idoneidad para asumir a cabalidad un puesto y velar por los intereses de la institución.

En Costa Rica, se han presentado diversas situaciones con intermediarios financieros, las cuales, pese a la experiencia y el conocimiento adquiridos, parecen apuntar a que no se aprende la lección con casos como el descalabro de las financieras en el segundo quinquenio de los años ochenta, el cierre del Banco Anglo Costarricense en 1994, la crisis del sector cooperativo a finales de los noventa, el caso de BICSA y los casos más recientes de Bancrédito y el Banco de Costa Rica.

Sobre estas dos últimas instituciones financieras, en la cuales se ha evidenciado de forma llana que dinero público ha sido mal administrado, con pérdidas considerables y riesgos innecesarios, se debe dar especial lectura al ambiente generado en torno al contexto de gestiones indebidas.

En congruencia con lo anterior, se analizan a continuación los retos y desafíos que la banca pública costarricense debe asumir en forma inmediata. También se establecen acciones necesarias para su fortalecimiento:

\section{Dotar a la banca nacional de un blindaje que la proteja de influencias políticas}

A nuestro criterio, es evidente la necesidad de revisar las estructuras y los procedimientos que actualmente se aplican en las entidades bancarias estatales, para determinar con claridad sus fortalezas y debilidades, en particular aquellos portillos que podrían ser usados por terceros con interés en sacar provecho de los recursos financieros que administran e incluso beneficiar de manera fraudulenta a otras personas o agrupaciones, al valerse de su investidura.

Con la propuesta anterior, se garantizaría contar con los mecanismos necesarios para ejercer una óptima gestión ejecutiva y administrativa, puesto que el manejo de los recursos se realizaría en función de los intereses corporativos de la banca y no respondiendo a intereses políticos, por lo que se lograría un blindaje contra el tráfico de influencias. 
La revisión de la normativa y los manuales de procedimientos resulta indispensable para asegurar que cada operación que se realice siga un orden lógico establecido, a fin de que se respete la lista de requerimientos necesarios, sin excepciones de ningún tipo, al tiempo que se crean los mecanismos necesarios para la gestión y mitigación del riesgo.

$\mathrm{Al}$ igual que en otras áreas, en finanzas y banca hay dos condiciones fundamentales que se asocian al conocimiento y manejo del esquema normativo: a) el cumplimiento continuo y obligatorio de todas y cada una de las normas; y b) la responsabilidad de individuos e instituciones de velar por su cumplimiento.

\section{Idoneidad de directivos y gerencias}

En cuanto a los nombramientos de los miembros de las juntas directivas y gerencias de las instituciones bancarias estatales, se considera que no pueden seguir bajo el control de los gobiernos de turno, ya que existe un riesgo latente de que se nombren en altos puestos a personas cuyo único mérito es haber hecho un favor político, usualmente en un proceso electoral.

De lo anterior, se colige la necesidad de implementar procesos de selección objetivos y despolitizados, en órganos confiables y competentes que evalúen candidaturas antes de realizar los nombramientos, para así colocar de manera óptima profesionales competentes que cuenten con las habilidades y capacidades para ejercer un cargo delicado y de confianza.

Por otro lado, hay que recalcar que es función de las juntas directivas aprobar políticas y procedimientos propuestos por la administración, orientadas a buscar la consolidación del negocio de banca pública. Desde este punto de vista, se debe reconocer que históricamente, a pesar de sus defectos, las juntas directivas de entidades como el Banco Nacional, el Banco de Costa Rica, el Banco Popular y en su momento Bancrédito han tenido éxito en consolidarse como instituciones de primer orden, tanto en lo nacional como en lo regional, y al hacerlo han logrado financiar a través de sus utilidades a sectores como el cooperativo, industrial, comercio, turismo y agropecuario, entre otros.

Por otro lado, en cuanto a la transparencia con que son nombrados los jerarcas y miembros de juntas directivas de bancos estatales, es un tema que urge revisar, en especial lo relativo a la normativa nacional vigente y la forma en que son seleccionados, pues ostentarán responsabilidades de alta relevancia en lo concerniente a la toma de decisiones sobre el manejo de decenas de cientos de miles de millones, propiedad de los costarricenses.

En cuanto al tema del nombramiento de personas idóneas para ejercer cargos de gobierno corporativo, es fundamental que cuenten con la formación profesional y la experiencia necesaria y requerida, a fin de que se garantice y respalde su adecuado aporte y desempeño en la entidad financiera que dirigirán.

\section{Fortalecimiento de mecanismos de protección de operaciones y de control interno}

Las instituciones bancarias manejan, dentro de su ámbito sectorial, dos tipos de operaciones: primero, las activas o de financiamiento, que se refieren al motor de generar utilidades y están conformada por sus diversas carteras crediticias (tarjetas de crédito, créditos hipotecarios y prendarios, banca personal y corporativa, entre otras); y segundo, las operaciones pasivas o inversiones, referentes a todas las captaciones realizadas (cuentas de ahorro, cuentas corrientes, certificados a plazo, etc.). La diferencia entre las operaciones bancarias activas y pasivas es la esencia del negocio de la banca.

Por otro lado, en cuanto a control interno se refiere, este comprende un complejo sistema dentro de las instituciones financieras que tiene como finalidad el velar porque todas y cada una de las actividades, operaciones, actuaciones y la administración de la información, entre otros, se realicen dentro de la normativa y el marco legal existentes; incluye todos aquellos métodos, planes, principios, procedimientos, mecanismos de verificación y evaluación. El control interno debe ejercer un papel protagónico adecuado e inteligente y no simplemente controlar por controlar, ya que esto produce entrabamiento.

En las juntas directivas y gerencias de las instituciones financieras existe un natural apetito por el riesgo y, al ser ellos los responsables de la toma de decisiones y reglas del negocio, deben poner límites en su accionar dentro del ámbito legal costarricense.

Las estructuras del sistema bancario y entidades financieras están técnicamente bien concebidas y existen mecanismos de idoneidad; sin embargo, continúan presentándose irregularidades en el sector bancario, como por ejemplo el tráfico de influencias para omitir requisitos, aligerar los trámites y así beneficiar a ciertos sectores o grupos. 
Las auditorías internas deberían consolidarse como agencias de cumplimiento tanto en el orden financiero como operativo y gubernamental, al utilizarse como herramienta constante de seguimiento y acentuar su injerencia no solo técnica, sino también actitudinal, en el acompañamiento al funcionario bancario, para que este se sienta controlado y así evitar que la toma de decisiones quede a la libre.

\section{Salvaguardar la reputación}

A nivel bancario, es conocido que la confianza es la base del negocio y parte de ella se traduce en la reputación de la cual goce la entidad. Esta reputación se puede definir como el conjunto de percepciones y expectativas que tienen sobre la empresa los diversos grupos de interés, por lo cual el respeto se gana y se transmite a través de su accionar.

Una excelente reputación permite a los intermediarios financieros adquirir ventaja competitiva sostenible y beneficios superiores, producto de la capacidad de contratar o retener a trabajadores mejor preparados a menor costo y lograr a su vez fidelizar la clientela, atraer inversores y clientes nuevos, entre otros. Al tratarse la banca de un negocio de absoluta confianza, el contar con una excelente reputación permitirá afianzarse, consolidar altos niveles de resultados y mejorarlos a través de la captación de nuevos clientes.

Tal como lo establece el Comité de Basilea, el riesgo asociado directamente a la reputación se considera multidimensional y se convierte en el reflejo de la imagen de los actores de los mercados financieros.

Reciente, situaciones como las denunciadas por los medios de comunicación en los últimos tres años con respecto a movimientos y operaciones cuestionables (por ejemplo, el caso de la importación de cemento chino en el cual se involucraron los bancos estatales junto con sus gobiernos corporativos) dañaron la buena imagen que por muchos años han construido las instituciones financieras estatales y quebrantaron la confianza de la sociedad en sus transacciones y mecanismos de control. Situaciones como estas abren una y otra vez en la memoria colectiva el fantasma del cierre del Banco Anglo Costarricense en septiembre de 1994.

En síntesis, sobre este punto se establece claramente que la reputación es el activo intangible más importante de una organización, especialmente la de índole financiera, ya que es la base de la confianza de los clientes y se percibe como un indicador de la eficiencia con la cual se desarrollan las acciones de la institución.

\section{Valoración del riesgo}

El riesgo es considerado todo aquel evento que de una u otra forma afecta en forma negativa el cumplimiento de los objetivos institucionales, por lo cual, del resultado de su valoración se desprende una serie de acciones de mejora para garantizar el adecuado cumplimiento de los objetivos estratégicos de la entidad.

Actualmente, las instituciones financieras poseen departamentos dedicados en exclusiva a la valoración del riesgo en todo el quehacer corporativo, lo cual incluye la evaluación del ambiente, de los diferentes riesgos por área de interés, la propuesta de actividades de control y su plan de ejecución, el proceso de comunicación corporativa y las actividades de supervisión.

Al determinar el origen de las diferentes amenazas que atentan contra la institución, se trabaja en los ámbitos externos y su relación con la eficiencia y eficacia de las operaciones; los ámbitos internos y la integridad de la información financiera; y los riesgos inherentes que tienen relación directa con el cumplimiento de la normativa nacional e internacional vigente.

Todos estos procesos de valoración de riesgos se traducen en actividades de mejora que en plazo inmediato deberían reflejarse en procesos internos y externos más eficientes y seguros, así como en un mejor servicio al cliente que generaría mayor confianza, tanto en la entidad como en los réditos de su transacción.

Está comprobado que se hace necesaria la especialización de las personas encargadas de gestionar el negocio del sector financiero, en especial si se considera que, a pesar de que la normativa existe formalmente, en ocasiones se buscan portillos para que se generen negocios no del todo legales, permitiendo así el incumplimiento de requisitos mínimos para garantizar la seguridad. 


\section{Amplio manejo del secreto bancario}

Para el caso de Costa Rica, el secreto bancario está amparado en el artículo 24 de la Constitución Política, el cual establece lo siguiente: "Se garantiza el derecho a la intimidad, a la libertad y al secreto de las comunicaciones. Son inviolables los documentos privados y las comunicaciones escritas, orales o de cualquier otro tipo de los habitantes de la República".

Para un país como Costa Rica, la jurisprudencia existe en dos sentidos; por un lado, se garantiza el secreto bancario; pero, por el otro, se permite a los entes encargados el poder fiscalizar la información documental para verificar la gestión implícita competente en los negocios financieros.

El concepto de secreto bancario ha sido desarrollado mediante la vía jurisprudencial. En ese sentido, la Sala Constitucional estableció, en las sentencias 2004-14201 y 2006-17518:

De todo lo anterior puede concluirse que el secreto bancario es la obligación impuesta a los bancos, sean públicos o privados, de no revelar a terceros los datos referentes a sus clientes que lleguen a su conocimiento como consecuencia de las relaciones jurídicas que los vinculan. Es un deber de silencio respecto de hechos vinculados a las personas con quienes las instituciones bancarias mantienen relaciones comerciales, así como una obligación profesional de no revelar informaciones y datos que lleguen a su conocimiento en virtud de la actividad a que están dedicados (el subrayado no pertenece al original).

La cobertura que la legislación da al secreto bancario incluye una serie de diligencias diarias. Así, sobre las actividades bancarias que se encuentran protegidas por el secreto bancario, la Sala Constitucional deliberó, en la sentencia 5781992, lo siguiente:

En general toda la actividad bancaria que involucre contratos, solicitudes y cualquier otro tipo de relación con particulares -como clientes-, está, por su naturaleza, amparada al secreto bancario. Las operaciones que efectúan los particulares con los bancos - como sujetos de derecho privado- constituyen tanto en su obtención como en la forma y el modo de su constitución y servicio, documentos privados que están amparados a la protección que establece el artículo 24 Constitucional -salvo que por su naturaleza deban constar en documentos públicos o en registros, también públicos, de los cuales, y sin intervención del banco, se podría obtener la información que ellos contengan-, así que el banco no puede suministrarla sino en los casos y en la forma que aquel artículo prevé para ello (el subrayado no pertenece al original).

Sobre el rol que tiene la Superintendencia General de Entidades Financieras (SUGEF) en la protección del secreto bancario, el tribunal constitucional expresó, en la sentencia 8127-1997, lo siguiente:

...por un lado la obligación - como regla- del órgano del Estado encargado de la supervisión de la actividad bancaria de guardar discreción sobre los datos que obtiene en el ejercicio de esa función, salvo las excepciones previstas, las que, en todo caso, deben seguir un trámite administrativo especial (...) Los deberes impuestos en las normas anteriores también resultan inherentes a la naturaleza de la actividad bancaria, y tienen como fin proteger la relación clientebanco, mediante el uso adecuado y legítimo de la información que este da a la institución financiera, de manera que no se defraude una confianza legítimamente depositada (el subrayado no pertenece al original).

En cuanto a las limitaciones al secreto bancario, la Sala Constitucional ha sido enfática en que los datos personales de interés privado requieren consentimiento de la persona, no siendo así necesariamente los datos del historial crediticio de la persona, los cuales eventualmente y, según el caso, podrían ser objeto de levantamiento del secreto bancario. Al respecto, en la sentencia 4749-1999, el órgano constitucional se pronunció:

$X$.- Sobre la necesidad de que el interesado dé su expreso consentimiento para la recolección y uso de datos referentes a su persona, esta Sala considera que ello es cierto cuando se trata de datos personales de interés meramente privado. No ocurre lo mismo respecto de la información que revele el historial crediticio de una persona, la cual es necesaria para la protección de una actividad mercantil de interés público y necesaria para el desarrollo, como lo es el crédito. En ese sentido, no resultaría lógico exigir que toda persona diera su expreso asentimiento para el almacenamiento de datos suyos referentes a créditos anteriores, pues posiblemente las personas con problemas de pago estarían renuentes a prestar sus datos, y asi el sistema perdería el sentido que tiene. Además, procede esta información de transacciones comerciales 
realizadas por el recurrente, mismas que no obedecen a una obligación de confidencialidad excepto que exista pacto expreso o que así lo indique la Ley. Por lo anterior, también en cuanto a este aspecto considera la Sala que no lleva razón el petente, por lo que deberá ser desestimado el recurso, como en efecto se hace (el subrayado no pertenece al original).

Siempre sobre esta línea del ordenamiento jurídico costarricense, el marco regulatorio sobre el secreto bancario se encuentra establecido en las siguientes normas:

Código de Comercio: el artículo 615 garantiza la inviolabilidad de las cuentas corrientes, para garantizar la confidencialidad de los negocios, sin demeritar la posibilidad de que la información pueda ser obtenida mediante mecanismos legales para alguna eventual fiscalización. Por su parte, el artículo 203 destaca la privacidad del negocio y recalca las sanciones para cualquier persona que la violente.

Código Penal: el artículo 232 bis expone las sanciones aplicables a funcionarios que divulguen información sensible de diferentes procesos.

Ley Orgánica del Banco Central de Costa Rica: el artículo 132 destaca la participación relativa de los funcionarios abocados en altos puestos o de otro tipo en la entrega de información confidencial; esto, al acogerse a lo que la ley les permite y las sanciones imperantes por algún eventual incumplimiento. En el artículo 133, se destaca la normativa a la cual debe acogerse la SUGEF u otros actores directos de la gestión al entregar o no información sensible a las partes y la correspondiente sanción si se violara el proceso de modo doloso o de otro tipo.

Ley Reguladora del Mercado de Valores: el artículo 108 está enfocado en orientar el quehacer de los participantes en el orden de acogerse estrictamente a los alcances solicitados por los clientes o abocarse estrictamente a lo que implica esta materia en el mercado. Por su parte, el artículo 151 cobija la autorización o potestad que acoge a la SUGEF de poder compartir información confidencial con instancias extranjeras similares a su quehacer, en tanto su gestión sea en correspondencia con la otra entidad en las mismas condiciones.

Ley sobre estupefacientes, sustancias psicotrópicas, drogas de uso no autorizado, legitimación de capitales y actividades conexas: los artículos 24 y 25 atribuyen la potestad a los órganos de supervisión y fiscalización en cuanto a su competencia para la atención de transacciones sospechosas o ilícitas. Igualmente, se destaca que estos actos deben comunicarse de oficio y de manera confidencial al ente de supervisión inmediato.

Código de Normas y Procedimientos Tributarios (Código Tributario): el artículo 106 se aboca a recapitular la jurisprudencia indicada en este texto y aplicable a la materia que atañe. Se recalca que en Costa Rica se cuenta con clara e importante legislación, normativa y jurisprudencia en cuanto a secreto bancario se refiere, pero este jamás debe interpretarse como un mecanismo de secretismo de las gestiones del gobierno corporativo, el cual más bien tiene la obligación y responsabilidad de rendir cuentas sobre la gestión realizada, para otorgar a la población transparencia, confianza y confidencialidad. Si bien existe suficiente legislación, normativa y jurisprudencia en el tema de secreto bancario, este es de vital importancia para garantizar la transparencia y confiabilidad de los negocios; sin embargo, no debe ser visto jamás como un mecanismo que interfiera en la rendición de cuentas, de manera tal que, ante cualquier proceso de investigación, se cuente con todos los datos necesarios para una resolución mejor.

\section{Estados financieros}

Para efectos de la presente investigación, es importante dimensionar que en las directivas y altas gerencias es donde se toman las decisiones estratégicas del negocio y se les ha confiado millones de millones de colones de clientes costarricenses, cuya salvaguarda depende de una acertada toma de decisiones. Por lo anterior, se trabaja con las cifras de los estados financieros auditados de cuatro bancos, información que se tomó de la página de la SUGEF.

Los autores tomaron en consideración los tres bancos comerciales del Estado costarricense: Banco de Costa Rica, Banco Nacional de Costa Rica y Bancrédito ${ }^{1}$, pero solo uno de los dos creados mediante leyes especiales: el Banco Popular y de Desarrollo Comunal, pues el Banco Hipotecario de la Vivienda en una entidad de segundo piso.

Como se mencionó al principio, debido a que miles de millones de colones propiedad de los costarricenses dependen

1 Bancrédito cerró operaciones mientras se llevaba a cabo esta investigación, por lo que toda la información contable obtenida se encuentra a septiembre de 2018. 
de las decisiones de las juntas directivas y altos mandos de los bancos, las personas que ostenten cargos de decisión deben conocer perfectamente el negocio de la banca y poseer suficiente idoneidad y sentido de responsabilidad al tomar acuerdos.Para un horizonte de tiempo de estudio de seis años, del 2013 al 2018, se presentan las tablas 3 y 4, en las cuales se incluye la información financiero contable de los cuatro bancos seleccionados: Banco de Costa Rica, Banco Nacional, Bancrédito y Banco Popular y de Desarrollo Comunal.

Tabla 3. Totales activo, pasivo y patrimonio, período 2013-2018 (cifras en miles de millones de colones).

Total Activo

\begin{tabular}{|c|c|c|c|c|c|c|c|}
\hline $\begin{array}{l}\text { Institución } \\
\text { Financiera }\end{array}$ & 2013 & 2014 & 2015 & 2016 & 2017 & 2018 & Promedio \\
\hline $\begin{array}{l}\text { Bancol de Costa } \\
\text { Rica }\end{array}$ & 3492,51 & 3909,68 & 4068,10 & 4548,56 & 4963,53 & 4851,84 & 4311,20 \\
\hline $\begin{array}{l}\text { Banco Nacional } \\
\text { de Costa Rica }\end{array}$ & 5055,33 & 5491,03 & 5886,82 & 6208,18 & 7033,98 & 6940,41 & 6102,62 \\
\hline $\begin{array}{l}\text { Banco Popular } \\
\text { y de Desarrollo } \\
\text { Popular }\end{array}$ & 2133,54 & 2452,43 & 2754,53 & 3028,09 & 3416,71 & 3530,45 & 2885,96 \\
\hline Bancrédito & 538,55 & 614,90 & 662,69 & 685,06 & 187,56 & 176,34 & 477,51 \\
\hline & & & & & & Pomedio Total & 3444,33 \\
\hline
\end{tabular}

Total Pasivo

\begin{tabular}{|c|c|c|c|c|c|c|c|}
\hline $\begin{array}{c}\text { Bancol de Costa } \\
\text { Rica }\end{array}$ & 3106,33 & 3523,50 & 3638,81 & 4096,33 & 4452,30 & 4295,61 & 3852,15 \\
\hline $\begin{array}{l}\text { Banco Nacional } \\
\text { de Costa Rica }\end{array}$ & 4600,90 & 4994,26 & 5347,93 & 5619,08 & 6409,74 & 6293,06 & 5544,16 \\
\hline $\begin{array}{l}\text { Banco Popular } \\
\text { y de Desarrollo } \\
\text { Popular }\end{array}$ & 1706,76 & 1980,95 & 2217,63 & 2429,25 & 2767,43 & 2845,84 & 2324,64 \\
\hline Bancrédito & 478,87 & 554,32 & 597,58 & 617,06 & 147,22 & 143,28 & 423,06 \\
\hline & & & & & & Pomedio Total & 3036,00 \\
\hline \multicolumn{8}{|c|}{ Total Patrimonio } \\
\hline $\begin{array}{c}\text { Bancol de Costa } \\
\text { Rica }\end{array}$ & 386,18 & 386,18 & 429,29 & 482,24 & 514,23 & 556,23 & 459,06 \\
\hline $\begin{array}{c}\text { Banco Nacional } \\
\text { de Costa Rica }\end{array}$ & 454,43 & 496,77 & 538,89 & 589,10 & 624,24 & 647,36 & 558,46 \\
\hline $\begin{array}{l}\text { Banco Popular } \\
\text { y de Desarrollo } \\
\text { Popular }\end{array}$ & 426,78 & 471,48 & 536,90 & 598,84 & 649,28 & 684,61 & 561,31 \\
\hline Bancrédito & 59,67 & 60,58 & 65,11 & 67,97 & 40,35 & 33,06 & 54,46 \\
\hline & & & & & & Pomedio Total & 408,32 \\
\hline
\end{tabular}

Fuente: elaboración propia.

\subsection{Totales de activos:}

Los activos corresponden al músculo con que cuentan los bancos para realizar sus operaciones; especial importancia tienen las carteras de crédito, pues allí se ubican estas cuentas y de las carteras depende la vida de los bancos, por ser la fuente principal de los ingresos.

En promedio, estos bancos manejaron, al cierre de 2018, activos por ф3 444 325210 022, cifra exorbitante para un ciudadano promedio, en el entendido de que cualquier buena o mala decisión tomada afecta o impacta significativamente esta cifra, debido a que estos activos permiten a los bancos la obtención de ingresos. 


\subsection{Totales de pasivos:}

Al tener el negocio de la banca una naturaleza de intermediación financiera pura, donde se capta a una tasa y se presta a una mayor, las cuentas del pasivo tienen una gran relevancia, puesto que es donde se ubican los registros contables del origen de los recursos que se destinan para ser invertidos (prestados) en cartera de crédito y se informa quién aportó los recursos necesarios para mantener la operatividad del banco. De ahí la importancia que tiene la imagen de confianza, ya que, si no se logra captar recursos, no se pueden realizar colocaciones en cartera nueva; en otras palabras, no hay intermediación financiera.

Para el cierre del período 2018, estos bancos manejaron en promedio ф3 036001887952 , cifra que refleja la confianza depositada por los clientes, quienes mantienen vivas las operaciones de la institución.

\subsection{Totales de patrimonio:}

El patrimonio corresponde a la parte residual de los activos de un banco una vez que se han rebajado todos los pasivos. Se incluyen los aportes con los que fue constituida la institución, así como los de capitalización de resultados de períodos anteriores.

Si bien es cierto que, en los estados financieros, el patrimonio es el rubro al que corresponde un monto menor, no significa que sea menos significativo o relevante; para el período 2018, le pertenece en promedio un total de ф4408 323 322 070. Cualquier decisión, buena o mala, afectará a esta partida.

Tabla 4. Resultados del período, efectivo y equivalente al final del año, período 2013-2018 (cifras en miles de millones de colones).

Resultados del período

\begin{tabular}{|c|c|c|c|c|c|c|c|}
\hline $\begin{array}{l}\text { Institución } \\
\text { Financiera }\end{array}$ & 2013 & 2014 & 2015 & 2016 & 2017 & 2018 & Promedio \\
\hline $\begin{array}{c}\text { Bancol de Costa } \\
\text { Rica }\end{array}$ & 30,66 & 21,85 & 43,11 & 52,95 & 31,99 & 20,46 & 33,50 \\
\hline $\begin{array}{l}\text { Banco Nacional } \\
\text { de Costa Rica }\end{array}$ & 35,63 & 43,26 & 43,12 & 50,20 & 35,14 & 23,12 & 36,41 \\
\hline $\begin{array}{c}\text { Banco Popular } \\
\text { y de Desarrollo } \\
\text { Popular }\end{array}$ & 28,94 & 30,02 & 49,26 & 43,47 & 28,07 & 14,83 & 32,43 \\
\hline Bancrédito & 4,15 & 0,91 & 4,53 & 2,87 & $-27,90$ & $-7,29$ & $-3,79$ \\
\hline & & & & & & Pomedio Total & 25,14 \\
\hline \multicolumn{8}{|c|}{ Efecto y equivalente al final del año } \\
\hline $\begin{array}{l}\text { Bancol de Costa } \\
\text { Rica } \\
\end{array}$ & 591,42 & 791,32 & 667,10 & 721,33 & 894,31 & 818,40 & 747,31 \\
\hline $\begin{array}{l}\text { Banco Nacional } \\
\text { de Costa Rica }\end{array}$ & 903,87 & 1002,12 & 995,21 & 1015,47 & 1496,78 & 1113,34 & 1087,63 \\
\hline $\begin{array}{c}\text { Banco Popular } \\
\text { y de Desarrollo } \\
\text { Popular }\end{array}$ & 295,30 & 329,72 & 353,00 & 365,15 & 482,21 & 537,92 & 394,72 \\
\hline Bancrédito & 89,31 & 96,80 & 125,81 & 110,84 & 11,27 & 35,06 & 78,35 \\
\hline & & & & & & Pomedio Total & 3036,00 \\
\hline
\end{tabular}

Fuente: elaboración propia.

\subsection{Resultados del período:}

El estado de resultados corresponde a las pérdidas o ganancias generadas en la operación del período. En él se muestra en forma numérica el producto de la intermediación financiera que se realiza en los bancos (captacióncolocación). 
Las decisiones, acertadas o no, durante el ejercicio del período 2018, se reflejan en este rubro y, dada su importancia, es donde se asocian las decisiones certeras a resultados satisfactorios, que en promedio, para estos cuatro bancos, corresponde a un monto de ф25 139138279.

\subsection{Efectivo y equivalentes al final del año:}

Indiscutiblemente, la liquidez que posea un banco es trascendental para su operación. Al observar la historia de la banca nacional, situaciones como las acontecidas con el Banco Anglo Costarricense en septiembre de 1994 y, más recientemente, entre los años 2017 y 2018 con Bancrédito, son reflejo vivo de que una entidad financiera puede cesar operaciones por pérdidas o por falta de liquidez necesaria para operar, aspectos que afectan también la reputación y confiabilidad en la banca.

El estado de efectivo y equivalente al final del año muestra el saldo neto de efectivo al terminar un período, discriminando el efectivo entrante y saliente, producto de la intermediación financiera (operación-inversiónfinanciación).

Para el cierre del período 2018, los cuatro bancos que hemos comentado manejaron en promedio ф577001593859, cifra que, como se ha explicado, es de vital importancia para operar. La delicadeza que tiene este rubro es que una mala gestión, un movimiento equivocado o un rumor pueden provocar una salida brusca de efectivo por parte de los ahorrantes y la entidad se quedaría sin liquidez para operar, situación experimentada por Bancrédito.

Todo lo expuesto denota que una mala decisión de los altos mandos de una entidad de intermediación financiera pone en riesgo miles de millones de colones que pertenecen a los costarricenses, dinero que precisamente debe ser manejado por los bancos para desarrollar la economía del país, la cual, dicho sea de paso, enfrenta al cierre del año 2019 un estancamiento que hace urgente la toma de medidas de reactivación inmediatas, siendo la banca un gran músculo para impulsar la producción nacional.

\section{CONCLUSIONES}

Definitivamente, el tema bancario siempre ha sido de mucha relevancia para la agenda de cualquier país y el impacto que ha tenido, tiene y tendrá en el desarrollo nacional hace que una impecable gestión de su gobierno corporativo sea clave para contribuir con el desarrollo de la nación.

Esto es particularmente importante en la coyuntura de desequilibrio fiscal en la cual se vive y que ha sido protagonista en la agenda del país durante los períodos 2018, 2019 y 2020, aunado a la necesidad de mejorar los resultados presentados por el Banco Central de Costa Rica, los cuales indican que, a febrero 2018, se presentó un déficit financiero de $0,7 \%$ del PIB, resultado del desbalance de $1,0 \%$ del Gobierno central, parcialmente compensado con el 0,4 \% del PIB producto de superávit de instituciones del sector público y un déficit financiero de 0,1 \% del PIB.

De esto es importante resaltar que el sector bancario mantiene activa y en crecimiento la economía del país, en el entendido de que una economía activa produce desarrollo y este, a su vez, contribuye a mejorar el PIB.

Por otro lado, existe una particularidad en cuanto a delitos que son exclusivamente bancarios y que se maximizan si se cometen en la banca. Por ejemplo, si un comisionista de una entidad privada pone de acuerdo al que compra y al que vende para obtener una comisión, se considera un acto totalmente lícito e incluso ha llegado a ser un oficio. Caso contrario si se presenta en la gestión pública, donde se tipifica como un delito.

Al mantener las juntas directivas y los jerarcas una independencia al aplicar la normativa, se logrará estandarizar para cualquier persona física o jurídica los requisitos y evitar así conflictos de intereses e irregularidades en las operaciones y garantizar que se recupere la inversión.

Según el análisis realizado, las normas existentes en Costa Rica son suficientes; el problema es que no se cumplen o que se encuentran los llamados "portillos" que convierten la excepción en la regla, con lo cual se facilita cometer delitos financieros.

En banca, la toma de decisiones por parte de los altos jerarcas es crucial para las finanzas de las instituciones. En casos como los del Banco de Costa Rica y Bancrédito, así como el del Banco Anglo Costarricense en su momento, la historia sería diferente si se hubiesen tomado las decisiones acertadas en el momento justo, decisiones que podrían haber evitado el cierre de instituciones financieras y pérdidas millonarias para la población. 
Se considera importante que en Costa Rica se cree una comisión legislativa permanente que pida cuentas claras y oportunas sobre los resultados del quehacer de las entidades bancarias públicas y privadas cada año, aprovechando el cierre anual de los estados financieros, una vez auditados.

Además, siempre con respecto a la propuesta de la comisión legislativa de banca, se propone que cada cierto tiempo los miembros de las juntas directivas de los bancos estatales rindan cuentas de sus actuaciones y resultados.

En cuanto a la normativa, esta debe ser revisada y actualizada periódicamente para un mejor control interno, desempeño y seguridad, con el fin de que las operaciones se realicen dentro del marco legal.

En el tema concerniente a la idoneidad y transparencia en el nombramiento de los miembros de las juntas directivas de los bancos del Estado, urge revisar la normativa vigente y la forma en que se seleccionan los directivos, para garantizar que las personas designadas cuenten con la formación profesional y la experiencia que aseguren y respalden un aporte adecuado al desempeño de la entidad financiera que van a dirigir y en la cual tomarán decisiones importantes sobre el manejo de decenas de cientos de miles de millones, propiedad de los costarricenses.

Por último, nunca se debe dejar de lado que las instituciones públicas y en especial las de intermediación financiera tienen la responsabilidad de velar tanto por el patrimonio personal, como por el del país. Es fundamental garantizar que todas sus acciones se desarrollen en un marco de total transparencia y legalidad, bajo la dirección de personas idóneas poseedoras de una ética profesional inquebrantable que proteja los recursos que les han sido confiados en administración.

\section{"Haz que la faceta pública y la privada del hombre sean una" Sócrates (470-399 a.C.)}

\section{REFERENCIAS}

Agüero Salazar, R. (1995). El Proceso de Formación de la Ley en Costa Rica. Asamblea Legislativa: Centro para la Democracia. Ames, F. (1999). Diccionario de Contabilidad y Finanzas. Madrid: Brosmac.

Brealey Myers, A. (2016). Principios de Finanzas Corporativas. Ciudad de México: McGraw-Hill.

Brigham, E. y Ehrhardt, M. (2016). Finanzas Corporativas. Ciudad de México.

Cordobés, M., Molina, S. y Muñoz, T. (2009). Manual de contabilidad financiera. Bilbao, España: Editorial Desclée de Brouwer.

Estupiñán, G. (2009). Estado de flujos de efectivo y de otros flujos de fondo. Bogotá, Colombia: Ecoe Ediciones.

González Sánchez, E., Hernández Aguilar, J., Espinoza Hernández, E., Armas Vallejos, G., Redondo Garro, J. y Rodríguez Smith, A. (2015). Finanzas Empresariales. Un Enfoque Multidimensional. Heredia, Costa Rica: EUNA.

Heras, J. (2004). Diccionario de Mercados Financieros. Madrid, España: Ediciones Deusto.

Morales Chavarría, S. (2016). Ticos piden más préstamos para construir casa. El Financiero. Recuperado de http:// www.elfinancierocr.com/finanzas/Sugef-prestamos-vivienda-construccion-bancos-creditos_0_1023497661.html

Procuraduría General de la República de Costa Rica. (2018). Sistema Costarricense de Información Jurídica. Recuperado de http://www.pgrweb.go.cr/scij/

Rodríguez Jara, D. (2016). Crédito y transacciones bancarias desde la perspectiva financiera en Costa Rica. San José, Costa Rica: Editorial Universidad Estatal a Distancia.

Rosenberg, J. (1999). Diccionario de administración y finanzas. Barcelona, España: Océano.

Sala Constitucional, Corte Suprema de Justicia de Costa Rica. (2019). Poder Judicial, Sistema de Consulta en Línea. Recuperado de https://pjenlinea.poder-judicial.go.cr/SistemaGestionEnLineaPJ/Publica/wfpConsultaTesauro.aspx

SINART, S. A. (20 de diciembre de 2018). UNA Mirada. Oficina de Comunicación UNA. Recuperado de https://www. youtube.com/watch? $\mathrm{v}=\mathrm{HfXy-i-qOk} 8$

Superintendencia General de Entidades Financieras (27 agosto de 2017). Circular 01-05. Recuperado de https://www. sugef.fi.cr/normativa/normativa_vigente/documentos/SUGEF\%201-05\%20(v50\%20diciembre\%202016)SGF2335-2016.pdf

Superintendencia General de Entidades Financieras. (2019). Estados auditados. Recuperado de https://www.sugef. fi.cr/servicios/Reportes/ReporteEstatico.aspx? ReporteAlias=EstadosAuditados\&sector=true 